IJ§ER

ISSN: 2149-5939
International Journal of Social Sciences and Education Research

Online, http://dergipark.gov.tr/ijsser

Volume: 3(3), 2017

\title{
Öğretmen adaylarının öğretim amaçlı bilişim teknolojileri kullanımına ilişkin görüşlerinin incelenmesi ${ }^{1}$
}

\author{
The examination of the opinions of pre-service teachers on usage of the information \\ technologies for educational purposes
}

İpek Som ${ }^{2}$

Received Date: 02 / 02 / 2017

Accepted Date: 03 / $06 / 2017$

\begin{abstract}
$\ddot{O} z$
Bu araştırmanın amacl, ĕgitim fakültesi son sınıfta öğrenim gören öğretmen adaylarının gelecekte kendi ögretimlerinde bilişim teknolojilerinin (BT) eğitsel kullanımına ilişkin görüşlerini tespit etmektir. Olgubilim deseninde tasarlanan araştırmanın çalışma grubu, maksimum çeşitlilik örneklemesi ile oluşturulmuştur. Araştırma, 2016-2017 eğitim-öğretim yılında eğitim fakültesi son sinıfta öğrenim gören 11 öğretmen adayı ile yürütülmüştür. Nitel verilerin toplanmasında yarı-yapılandırılmış görüşme formu kullanılmıştır. Verilerin analizi için içerik analizi tekniği kullanılmıştır. Araştırma verilerinin analizi sonucunda elde edilen bulgular; öğretimin $B T$ ile bütünleştirilmesine ilişkin tanımlar, BT bilgisi, ögretimde BT kullanımın să̆ladiğ katkı ve BT kullanımının olumsuz tarafları, BT kullanım yeterlilikleri ve lisans eğitim sürecine yönelik önerileri başlıkları altında toplanmıştır. Ayrıca ögretmen adaylarının öğretimde bilişim teknolojileri kullanımına ilişkin olumlu görüşlere sahip oldukları belirlenmiştir.
\end{abstract}

Anahtar sözcükler: Bilişim Teknolojileri, Öğretim, Öğretmen Adayı

\begin{abstract}
The main aim of this research is to determine the opinions of the pre-service teachers studying in the final year of an education faculty regarding the educational use of information technology (IT) in their own teaching in the future. The research is designed as a phenomology. Maximum variation sampling was chosen to obtain more detailed information from the participants. The research was conducted with 11 pre-service teachers studying in final year at an education faculty during the 2016-2017 academic year. The qualitative data were collected through semi-structured interview form and analyzed with content analysis method. As a result of the analysis, the findings are grouped under these headings: definitions for integration of IT into teaching, knowledge of IT technologies, competencies related to IT use, contribution of IT to the teaching, negative aspects of IT use and suggestions for undergraduate education. In addition, it was found that pre-service teachers had positive views about the usage of information technologies in teaching.
\end{abstract}

Keywords: Information Technologies, Teaching, Pre-service teacher

\section{Giriș}

Öğretimin kalitesini arttırarak, öğretimin amaçlarına ulaşması, bireyleri gerçek hayata hazırlaması ve etkili öğrenmeler sağlanmasında en güncel görsel ve işitsel araçlar olarak bilişim teknolojileri (BT) öğrenme ortamlarında her geçen gün daha fazla yer bulmaktadır. Öğretime BT’nin dahil edilmesi; öğrencinin bilgiyi aktif olarak edinmesi, düşünme becerilerinin gelişmesi, öğrenci katılımı ve öğrenenlerin bireysel farklarının desteklenmesini sağlayarak

${ }^{1}$ Bu çalışma 27-29 Nisan 2017 tarihinde yapılan ICSSER - $3^{\text {rd }}$ International Conference on Social Sciences and Education Research'ta sözlü bildiri olarak sunulmuştur.

${ }^{2}$ Research Asst., İpek Som Önal, Y1ldız Technical University, İstanbul/TURKEY, som.ipek@gmail.com 
Som, İ. (2017). The examination of the opinions of pre-service teachers on usage of the information technologies for educational purposes. International Journal of Social Sciences and Education Research, 3(3), 882898.

öğrenme ortamlarını zenginleştirme ve öğrenmeyi arttırması açısından büyük önem taşımaktadır (Mandell, Sorge \& Russell, 2002; Cüre \& Özdener, 2008; Göktaş, Yıldırım \& Yıldırım, 2009; Bhasin, 2012). BT'nin öğretimin amaçlarına ulaşması ve öğrenmeye olan katkılarının ortaya çıkmasıyla birlikte öğretimde kullanımını yaygınlaştırmak için birçok ülkede eğitimde çeşitli ulusal girişimler de gerçekleştirilmiştir. Bu doğrultuda Türkiye'de teknolojideki gelişmelere paralel olarak güncel araç ve uygulamaların eğitimin her aşamasında kullanılmasını benimseyen bir eğitim politikası izlenmektedir.

Türkiye'de okullarda bulunan teknolojinin iyileştirilmesi, bu teknolojilerin eğitim sistemiyle bir bütün haline getirilmesi, öğrenci, öğretmen ve yöneticilerin bu teknolojilerin kullanımı hakkında eğitilmesi amacıyla 1980'li yıllardan günümüze çalışmalar yapılmaktadır (Saban, 2007; Uşun, 2003). Milli Eğitim Bakanlığ tarafından yürütülen bu çalışmaların en kapsamlısı 2010 yılında uygulamaya konulan Fırsatları Arttırma ve Teknolojiyi İyileştirme Hareketi (FATİH) projesidir. Bu projeyle eğitim kalitesinin arttırılması, eğitimde firsat eşitliğinin sağlanması, öğrenenlere daha fazla duyu organlarına hitap edecek şekilde internet altyapısı, akıllı tahta, tablet bilgisayar başta olmak üzere çeşitli bilgi ve iletişim teknolojisi araçlarının tüm düzeydeki öğretim kurumlarında derslerde etkili kullanımının sağlanması amaçlanmaktadır. Proje kapsamında okulöncesi, ilköğretim ile ortaöğretim düzeyindeki tüm okullara ağ altyapısı, çok fonksiyonlu yazıcılar; sınıflara etkileşimli tahtalar sağlanması hedeflenmiştir. Aynı zamanda öğretmenlere ve öğrencilere tablet bilgisayarlar verilmiştir. Öğretim programlarının BT ile uyumlu hale getirilmesi amacıyla eğitsel elektronik içerikler Eğitim Bilişim Ağı'nda (EBA) çevrimiçi olarak sunulmaktadır (MEB, 2017).

Öğretimde teknoloji kullanımını geliştirmeyi amaçlayan ulusal girişimlere rağmen öğrenme ortamlarının BT ile bütünleştirilmesinin istenilen düzeyde gerçekleşmediği görülmektedir (Mwalongo, 2011). Kurt(2014)'a göre; okullarda uygun teknolojik araçlar bulunmasına rağmen, öğretmenler bunların eğitsel amaçlı kullanımında başarısız olabilmektedirler. Buradan anlaşılacağı üzere, öğrenci öğrenmelerini arttırmak amacıyla BT’nin öğretime dahil edilmesi donanım ve yazılım araçlarının sağlanması dışında öğretmen, öğrenci, yönetici vb. birçok dinamik değişkenden doğrudan ya da dolaylı olarak etkilenmektedir (Cuban, Kirkpatrick \& Peck, 2001; Ertmer, 2005; Yıldırım, 2007). Öğretimin amaçları doğrultusunda BT'nin etkili kullanımında öğretmenlerin anahtar bir role sahip olduğu belirtilmektedir. Alanyazında öğretimde BT kullanımını etkileyen nedenler arasında belirtilen; BT’nin resmi öğretim programlarına dâhil edilmesi (Köksal, Yaman \& Saka 2016), hizmet içi eğitimlerin niteliği (Earle, 2002; Işıkoğlu, 2002; Shoepp, 2005), yönetici desteğinin (Lim ve Khine, 2006) yanı sıra BT kullanımına yönelik öğretmenlerin tutumları (Albirini, 2006; Mueller, Wood, Willoughby, Ross \& Specht, 2008; Tezci, 2009; Gibonne, Rukavina \& Silverman, 2010; Hue \& Jalil, 2013) ve hizmet öncesi dönemde aldıkları eğitim (Kubiatko, Usak, Yilmaz \& Tasar, 2010) en önemli unsurlar olarak görülmektedir. BT'nin etkili kullanımının, öğretmenlerin sahip oldukları niteliklerle yakından ilişkili olduğu ifade edilebilir. Buna ek olarak; Ward ve Parr (2010) araştırmalarında; öğretmenlerin öğretimde BT kullanımlarını etkileyen birincil faktörün algılanan ihtiyaç olduğunu ortaya koymaktadır. Öğretmenlerin, düz anlatım gibi yenilikçi uygulamaları içermeyen geleneksel öğretim yaklaşımlarına bağımlı kalarak dersi daha hızlı ve iyi öğretebileceklerine inanabilecekleri ve yenilikçi uygulamalardan kaçınabilecekleri belirtilmektedir. Öğretmenler donanım ve yazılımları kullanım becerilerine sahip olsalar dahi 
Som, İ. (2017). Öğretmen adaylarının öğretim amaçlı bilişim teknolojileri kullanımına ilişkin görüşlerinin incelenmesi. International Journal of Social Sciences and Education Research, 3(3), 882-898.

eğer bunların öğretimde faydalı olabileceğine dair bir inanca sahip değillerse bu becerilerini kullanmayacakları sonucu çıkarılabilir (Ertmer, 2005).

$\mathrm{Bu}$ bağlamda; teknolojinin hızlı değişimi, özellikle FATïH Projesi ile Türkiye'deki okullarda teknoloji koşullarının iyileştirilmesi ve bu teknolojilerin öğretim amaçları doğrultusunda kullanımının artması; geleceğin uygulayıcıları olarak öğretmen adaylarının eğitsel teknoloji kullanımına ilişkin görüş ve istekliliklerinin göz önünde bulundurulmasını önemli kılmaktadır (Kayaduman, Sırakaya, Seferoğlu, 2011; Banoglu, Madenoglu, Uysal \& Dede, 2014).

Ulaşılan alan yazında eğitsel BT kullanımını öğretmen adaylarının görüşleri açısından ele alan çeşitli araştırmalar bulunmaktadır. Bu araştırmalar; öğretmen adaylarının temel bilişsim teknoloji araçlarına yönelik görüşleri(Çetin, Önal \& Gündüz, 2015), eğitsel teknoloji kullanımının olumlu ve olumsuz yönleri hakkındaki görüşleri (Özen, 2013; Akkaya, 2016; Öçal \& Şimşek, 2016), öğretmen adaylarının eğitsel teknoloji kullanımını etkileyen faktörler (Aslan \& Zhu, 2015), BT kullanımına hazır olma durumlarını (Baydaş \& Göktaş, 2016) incelemektedir.

$\mathrm{Bu}$ araştırmada, eğitim fakültesi son sınıfta öğrenim gören öğretmen adaylarının gelecek öğretimlerinde kullanımlarını öngörmesi açısından, bilişim teknolojilerinin öğretim amaçlı kullanımına ilişkin görüşlerinin ortaya çıkarılması amaçlanmaktadır. Bu amaç doğrultusunda öğretmen adaylarının bilişim teknolojileri bilgisi, bilişim teknolojileri kullanımı ile ilgili yeterlikleri, teknoloji kullanımının sağlayacağı yararlar ve olumsuz taraflarına ilişkin görüşleri incelenmektedir. Öğretmen adaylarının görüşleri, bilişim teknolojilerinden eğitsel olarak daha etkili yararlanmaları ve uygulamalarına dahil etmelerinde önemli rol oynamaktadır (Çelik \& Kahyaoğlu, 2007). Araştırma sonuçları, lisans eğitiminde öğretmen adaylarının gerekli nitelikleri kazanmaları için yapılacak düzenlemelere katkıda bulunabilir.

\section{Yöntem}

\subsection{Araştırmanın deseni}

$\mathrm{Bu}$ araştırma, nitel araştırma desenlerinden olgubilim (fenomoloji) deseninde tasarlanmıştır. Olgu kavramı; olaylar, algılar, yönelimler, kavramlar ve durumlar olarak tanımlanır. Olgubilim, olguyu deneyimleyen veri kaynaklarından detaylı bilgi edinmek için tercih edilmektedir (Yıldırım ve Şimşek, 2011). Araştırmada, öğretmen adaylarının BT’nin eğitsel amaçlı kullanımı ile ilgili görüşleri yine onların açıklamaları ve örnekleriyle anlaşılmaya çalışıldığından olgubilim deseninden yararlanılmıştır.

\section{2. Çalışma grubu}

Araştırmanın çalışma grubunu; İstanbul'da bir eğitim fakültesinde 2016-2017 eğitim-öğretim yılında son sınıfta öğrenim görmekte olan öğretmen adayları oluşturmaktadır. Tablo 1'de çalışma grubunu oluşturan katılımcıların cinsiyet, yaş ve bölümlerine ait veriler sunulmaktadır. Araştırma katılımcıları belirlenmesinde amaçlı örnekleme yöntemlerinden maksimum çeşitlilik yöntemi kullanılmıştır. Maksimum çeşitlilik yöntemi, ihtiyaç duyulan bilgi açısından zengin durumların seçilmesine olanak tanımaktadır (Patton, 2014). 
Som, I. (2017). The examination of the opinions of pre-service teachers on usage of the information technologies for educational purposes. International Journal of Social Sciences and Education Research, 3(3), 882898.

Tablo 1. Çalışma grubunu oluşturan katılımcı özellikleri

\begin{tabular}{ccccc}
\hline Sıra no & Cinsiyet & Yaş & Öğrenim Gördüğü Bölüm & $\begin{array}{c}\text { Kullan1lan } \\
\text { kisaltma }\end{array}$ \\
\hline 1 & $\mathrm{~K}$ & 21 & İlköğretim Matematik Öğrt. & Ö1k \\
2 & $\mathrm{~K}$ & 21 & İköğretim Matematik Öğrt. & Ö2k \\
3 & $\mathrm{~K}$ & 21 & İlköğretim Matematik Öğrt. & Ö3k \\
4 & $\mathrm{E}$ & 22 & İngilizce Öğretmenliği & Ö4e \\
5 & $\mathrm{E}$ & 21 & İngilizce Öğretmenliği & Ö5e \\
6 & $\mathrm{~K}$ & 22 & Fen Bilgisi Ögretmenliği & Ö6k \\
7 & $\mathrm{~K}$ & 21 & Fen Bilgisi Öğretmenliği & Ö7k \\
8 & $\mathrm{~K}$ & 21 & Fen Bilgisi Öğretmenliği & Ö8k \\
9 & $\mathrm{~K}$ & 21 & Okul Öncesi Öğretmenliği & Ö9k \\
10 & $\mathrm{~K}$ & 21 & Okul Öncesi Öğretmenliği & Ö10k \\
11 & $\mathrm{E}$ & 24 & Okul Öncesi Öğretmenliği & Ö11e \\
\hline
\end{tabular}

Katılımcıların BT'nin eğitsel kullanımı hakkında bir yaşantıya sahip olmaları istendiği için son sınıf olmaları, bilgisayar 1, bilgisayar 2, öğretim teknolojileri ve materyal tasarımı derslerini almış olmaları tercih edilmiştir. Araştırmanın çalışma grubu, farklı bölümlerden 11 gönüllü öğretmen adayının katılımıyla oluşturulmuştur. Olgubilim araştırmalarında katılımcı sayısının 6 ile 12 arası olması tercih edilmelidir. (Patton, 2014). Görüşme kayıtlarının çözümü ve elektronik ortama aktarılmasında öğrenciler Ö1k, Ö2k, Ö3k, ..., Ö11e olarak kodlanmıştır.

\subsection{Veri toplama aract}

Araştırma verileri yarı yapılandırılmış görüşme formu aracılı̆̆ıyla toplanmıştır. BT’nin eğitsel kullanımına yönelik ilgili ulusal ve uluslararası alan yazın taraması yapılmıştır. Araştırma konusuna alan yazında var olan içerik doğrultusunda açık uçlu görüşme soruları hazırlanmıştır. Hazırlanan açık uçlu sorular üç doktora öğrencisi ile paylaşılarak görüş alınmıştır. Sonrasında bir öğretmen adayıyla pilot uygulama yapılarak araştırmanın amacına uygun olacak şekilde yarı yapılandırılmış görüşme formuna son şekli verilmiştir. Görüşme formunun ilk bölümü, katılımcıların demografik bilgilerini belirlemeyi amaçlamaktadır. İkinci bölümü, öğretimde BT kullanımına yönelik öğretmen adaylarının görüşlerini tespit etmeyi hedefleyen 7 soru ve 4 sonda soru olmak üzere toplamda 11 açık uçlu soru içermektedir.

\subsection{Veri toplama süreci}

Görüşmelerin gerçekleştirilebilmesi için her öğretmen adayı ile önceden görüşülerek gönüllü olarak katılmak isteyenlerle görüşme için randevu oluşturulmuştur. Görüşmeler yüz yüze görüşmeler olarak yürütülmüş̧ür. Katılımcılara görüşmenin başlangıcında araştırmanın amacı hakkında bilgi verilmiş, gönüllü olarak katıldıklarını sözlü olarak ifade etmeleri istenmiş ve bu kayıt altına alınmıştır. Veri toplama sırasında katılımcılara demografik bilgileri ve veri toplama aracında belirtilen 11 açık uçlu soru sorulmuştur. Tüm görüşmeler, görüşmenin akıcılığı için en elverişli yol olan ses kayıt cihazıyla kayıt altına alınmıştır. Görüşme kayıtları, araştırmacı tarafından yazıya dökümü yapıldıktan sonra katılımcılara gönderilerek katılımcı teyidi alınmıştır.

\subsection{Verilerin analizi}

Görüşmelerden elde edilen nitel verilerin analizinde; toplanan verileri açıklayabilecek kavramlara ve ilişkilere ulaşmayı sağlayan içerik analizi tekniği kullanılmıştır (Yıldırım \& Şimşek, 2013). Görüşme çözümlemelerinin yapılması işleminden sonra, araştırmacı tarafından 
Som, İ. (2017). Öğretmen adaylarının öğretim amaçlı bilişim teknolojileri kullanımına ilişkin görüşlerinin incelenmesi. International Journal of Social Sciences and Education Research, 3(3), 882-898.

rastgele seçilen bir veri setinden görüşme soruları dikkate alınarak kodlar üretilmiş ve bir kodlama anahtarı hazırlanmıştır (Babbie, 2010). Sonrasında araştırmacı dışında iki uzmanın rastgele seçilen birer veri setini kodlamaları sağlanmış ve içerik analizinde güvenirliği gösteren uyuşum yüzdesi hesaplanmıştır (Miles \& Huberman, 1984; akt. Türnüklü, 2000). Kodlayıcılar arasındaki uyumu gösteren bu değer .77 olarak bulunmuştur. Bulunan bu değer, araştırmanın güvenilirliğine işaret etmektedir.

\subsection{Geçerlik ve Güvenirliğin Sağlanması}

Araştırmanın geçerliğini arttırmak için, görüşme çözümlemeleri katılımcılara elektronik posta yoluyla iletilerek yanıtlarını incelemeleri ve doğruluğunu teyit etmeleri sağlanmıştır. Toplanan veriler, eleştirel bir gözle sorgulanarak ulaşılan sonuçların gerçeğe uygunluğu denetlenmiştir (Yıldırım\&Şimşek, 2013, s. 292). Ayrıca analiz sonuçları için veri kaynaklarından detaylar verilmesine dikkat edilmiştir. Katılımcıların görüşme sırasında söyledikleri bazı cümlelere doğrudan alıntı yapılarak yer verilmiştir. Araştırmanın dış geçerliğinin sağlanması amacıyla analiz süresince kullanılan kod anahtarı araştırmacıdan talep edildiği takdirde sunulabilir. (Creswell, 2007; Patton, 2014).

Araştırma güvenirliği, veri analizi sürecinde birden çok kodlayıcı ile tutarlılığın desteklenmesi, veri toplama ve analiz aşamalarının ayrıntılı olarak betimlenmesi yoluyla temin edilmiştir. Ayrıca görüşmelerden önce yapılan pilot çalışma ile görüşme soruları ve görüşme sürecinin işleyişi incelenmiş ve gerekli görülen önlemler alınmıştır.

\section{Bulgular}

$\mathrm{Bu}$ bölümde, öğretmen adaylarının öğrenme ortamlarında bilişim teknolojilerinin eğitsel kullanımına ilişkin görüşlerinin analizinden elde edilen bulgular 6 başlık altında sunulmaktadır. Bu başlıklar öğretmen adaylarının (1)Öğretimin BT ile Bütünleştirilmesine İlişkin Tanımları, (2) Öğretimde Kullanılabilecek BT Bilgisi, (3) Öğretimde BT Kullanımın Katkısı, (4) Öğretimde BT Kullanımın Olumsuz Tarafları, (5) Öğretimde BT Kullanım Yeterlilikleri, (6) Lisans Eğitim Sürecine Yönelik Önerileri ile ilgili görüşleri olarak şekillenmiştir.

\section{1. Öğretmen adaylarının ögretimin BT ile bütünleştirilmesine ilişkin tanımları}

Öğretmen adaylarının öğretim ile bilişim teknolojilerinin bütünleştirilmesine ilişkin tanımları Tablo 2 'de sunulmaktadır. Öğretmen adaylarına öğretim ile bilişim teknolojilerinin bütünleştirilmesini nasıl açıklarsınız sorusu yöneltilmiştir.

Tablo 2. Öğretmen adaylarının öğretimin BT ile bütünleştirilmesine ilişkin tanımları

\begin{tabular}{|c|c|c|c|c|c|c|c|c|c|c|c|c|c|}
\hline $\begin{array}{l}\text { Görüşler } \\
\text { (kodlar) }\end{array}$ & $\stackrel{\ddot{Z}}{\overline{0}}$ & 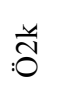 & $\frac{\mu}{m}$ & $\stackrel{0}{0}$ & $\stackrel{\infty}{0}$ & $: \frac{y}{0}$ & $\stackrel{\frac{y}{S}}{0}$ & $\stackrel{\ddot{4}}{0}$ & $\stackrel{\ddot{O}}{0}$ & $\frac{y}{0}$ & $\stackrel{0}{=0}$ & $\mathrm{f}$ & $\%$ \\
\hline $\begin{array}{l}\text { Öğretimle teknolojinin bir arada } \\
\text { sunulması / birleştirilmesi }\end{array}$ & & & $\checkmark$ & $\checkmark$ & & $\checkmark$ & & $\checkmark$ & $\checkmark$ & $\checkmark$ & & 6 & 54.54 \\
\hline Fatih projesi & $\checkmark$ & & & & $\checkmark$ & & & & & & & 2 & 18.18 \\
\hline Akıllı tahta kullanımı & $\checkmark$ & $\checkmark$ & & & & & & & & & & 2 & 18.18 \\
\hline $\begin{array}{l}\text { Dersin amaçlarına hizmet edecek } \\
\text { şekilde ders kapsamında teknolojinin } \\
\text { bulunması }\end{array}$ & & & & & & & $\checkmark$ & & & & & 1 & 9.09 \\
\hline STEM uygulamaları & & & & & & & & & & & $\checkmark$ & 1 & 9.09 \\
\hline
\end{tabular}


Som, İ. (2017). The examination of the opinions of pre-service teachers on usage of the information technologies for educational purposes. International Journal of Social Sciences and Education Research, 3(3), 882898.

Öğretmen adaylarının altısı (\%54.54) öğretimle teknolojinin bir arada sunulması olarak tanımlamaktadır. Öğretmen adaylarının ikisi (\%18.18) Fatih projesi, iki öğretmen adayı akıllı tahta kullanımı (\%18.18) olarak tek bir ifade ile yanıtlamıştır. Bir öğretmen adayı (\%9.09) dersin amaçlarına hizmet edecek şekilde ders kapsamında teknolojinin bulunması olarak tanımlamıştır. Diğer bir öğretmen adayı (\%9.09), öğretimle teknolojinin bütünleştirilmesini STEM uygulamaları olarak açıklamıştır. Bu tanımlara ilişkin olarak katılımcı ifadeleri aşağıda verilmektedir:

"Öğretimle teknolojiyi bir arada sunma, kolay bir şekilde ikisini bir arada götürme olarak açıklarım” (Ö3k). "Şöyle bir şey duydum; STEM uygulamaları. Bununla ilişskili gördüm” (Ö11e). "Fatih projesini biliyorum. Onun haricinde okullara gelen akull tahtalar. Fazla bir bilgim yok” (Ö1k).

Öğretmen adaylarının öğretimin bilişim teknolojileriyle bütünleştirilmesi kavramına ilişkin ayrıntılı tanımlar yapmadıkları ve tanımlarının sınırlı kaldığı görülmektedir.

\section{2. Öğretmen adaylarının ögretimde kullanılabilecek BT bilgisi}

Öğretmen adaylarına, öğretimde kullanılan BT bilgilerini belirlemek amacıyla öğretimde hangi teknolojik araç ya da uygulamalar kullanılabilir sorusu yöneltilmiştir. Öğretmen adaylarının yanıtları Tablo 3'de sunulmaktadır.

Tablo 3 incelendiğinde öğretmen adaylarının çoğunluğu projeksiyon cihazı (\%63.63) ve bilgisayarı (\%54.54) kullanılabilir teknolojiler olarak belirtmiştir. Bunun ardından beş öğretmen adayı (\%45.45) Eğitim Bilişim Ağı'nı, üç öğretmen adayı (\%27.27) ise akıllı tahtanın kullanılabilir olduğunu ifade etmiştir. Bunun haricinde mobil uygulamalar, çeşitli internet siteleri, eğitim portallarına sınırlı sayıda örnekler vermişlerdir. Fatih Projesi'nin önemli unsurlarından biri olan Tabletin kullanımından iki öğretmen adayı (\%18.18) bahsetmiştir. Bir öğretmen adayı office yazılımlarını (\% 9.09) ve diğer bir öğretmen adayı (\% 9.09) televizyonu öğretimde kullanılabilecek teknolojiler olarak ifade etmiştir.

Tablo 3. Öğretmen adaylarının öğretimde kullanılabilecek BT bilgisi

\begin{tabular}{|c|c|c|c|c|c|c|c|c|c|c|c|c|c|}
\hline $\begin{array}{l}\text { Görüşler } \\
\text { (kodlar) }\end{array}$ & $\stackrel{y}{0}$ & $: \frac{\pi}{\mathbb{N}}$ & $\frac{u}{\mathrm{~m}}$ & $: 0$ & $\because$ & $\stackrel{4}{0}$ & $\underset{0}{\stackrel{4}{5}}$ & $\frac{\breve{y}}{0}$ & $\frac{\pi}{\partial}$ & $\frac{y}{0}$ & $\stackrel{0}{=}$ & $\mathrm{f}$ & $\%$ \\
\hline Projeksiyon & & $\checkmark$ & & $\checkmark$ & & & $\checkmark$ & $\checkmark$ & $\checkmark$ & $\checkmark$ & & 7 & 63.63 \\
\hline Bilgisayar & & $\checkmark$ & & & & $\checkmark$ & $\checkmark$ & $\checkmark$ & $\checkmark$ & $\checkmark$ & & 6 & 54.54 \\
\hline EBA (ĕgitim bilişim ă̆l) & $\checkmark$ & & $\checkmark$ & & & & $\checkmark$ & $\checkmark$ & & & $\checkmark$ & 5 & 45.45 \\
\hline Ak1llı Tahta & $\checkmark$ & & & & & & $\checkmark$ & $\checkmark$ & & & & 3 & 27.27 \\
\hline $\begin{array}{l}\text { Mobil Uygulamalar (geometri yazılımı, } \\
\text { kahoot.it, karekod, web 2.0) }\end{array}$ & $\checkmark$ & & & $\checkmark$ & $\checkmark$ & & & & & & & 5 & 27.27 \\
\hline $\begin{array}{l}\text { İnternet Siteleri (sanal panaromik } \\
\text { gerçeklik, eğitimhane, hotpotatos, fen } \\
\text { okulum) }\end{array}$ & & & & $\checkmark$ & & & $\checkmark$ & & & $\checkmark$ & & 4 & 27.27 \\
\hline Hazır içerik (vitamin) & & & $\checkmark$ & & & $\checkmark$ & & $\checkmark$ & & & & 4 & 27.27 \\
\hline Tablet & $\checkmark$ & & & $\checkmark$ & & & & & & & & 3 & 18.18 \\
\hline Office yazılımı & & & & & $\checkmark$ & & & & & & & 3 & 9.09 \\
\hline Televizyon & & & & & & & & & $\checkmark$ & & & 1 & 9.09 \\
\hline
\end{tabular}


Som, İ. (2017). Öğretmen adaylarının öğretim amaçlı bilişim teknolojileri kullanımına ilişkin görüşlerinin incelenmesi. International Journal of Social Sciences and Education Research, 3(3), 882-898.

Bazı öğretmen adaylarının öğretimde kullanılabilecek BT araç ve uygulamalarına ilişkin ifadeleri aşağıda verilmektedir:

"Akıllı tahta, projeksiyon kullaniliyor. Hot Potatos var, Fen Okulum var. Hot Potatos'ta dersin içeriğine göre yer alan bilgi setleri var. "Fenokulum'da aynı şekilde..EBA vardı" (Ö7k). "Projeksiyonlar kullanılabilir. Şu an güncel olarak benim bildiğim bilgisayarlar, projeksiyonlar, akıllı tahta var. Vitamin var mesela, o güzel oluyor fen öğretimi açısından baktığınızda..." (Ö8k).

Öğretmen adaylarının yüksek oranda geleneksel olan araçlardan bahsettikleri ve sınırlı sayıda öğretmen adayının ifade ettiği uygulamaları nerede öğrendikleri sorulduğunda ise lisans derslerinden akıllarında kaldığı yönünde görüş bildirmişlerdir.

\section{3. Öğretmen adaylarının öğretimde BT kullanımın katkısına yönelik görüşleri}

Öğretmen adaylarına öğretimde BT kullanımının sağlayacağı faydalar sorulmuş ve yanıtlarından yola çıkarak elde edilen bulgular Tablo 4'de sunulmaktadır. Öğretmen adaylarının büyük çoğunluğu BT kullanımının öğrenilenleri somutlaştırmaya yarayacağını (\%72.72) ifade etmiştir. Ayrıca yedi öğretmen adayı (\%63.63) BT kullanımının derse görsellik katma yönünden yararlı olduğunu belirtmiştir. Öğrenilenlerin somutlaştırılması ve derslere görsellik kazandırmasıyla ilgili olarak bir öğretmen adayının görüşü şu şekildedir:

“Öğretmen açısından zaman kazandırıcı olur. Öğrenciye somut gösterebileceği şeyler olabilir ... Onun haricinde resimlerle, görseller katkı sağlayabilir... somut daha akılda kalıcı oluyor. O yüzden ögrrenci içinde çok daha yararlı olur bu durum” (Ö2k).

Tablo 4. Öğretmen adaylarının öğretimde BT kullanımın katkısına yönelik görüşleri

\begin{tabular}{|c|c|c|c|c|c|c|c|c|c|c|c|c|c|}
\hline $\begin{array}{l}\text { Görüşler } \\
\text { (kodlar) }\end{array}$ & $\ddot{\bar{Z}}$ & $\frac{\breve{~}}{0}$ & $\frac{\pi}{m}$ & $\stackrel{\mathscr{*}}{0}$ & $: 0$ & : & $\frac{\mathscr{A}}{0}$ & $\stackrel{\breve{\infty}}{: 0}$ & $\ddot{\mathscr{O}}$ & $\frac{y}{0}$ & $\stackrel{0}{=}$ & $\mathrm{f}$ & $\%$ \\
\hline Öğrenilenlerin somutlaşmasını sağlar. & $\checkmark$ & $\checkmark$ & $\checkmark$ & $\checkmark$ & & & & $\checkmark$ & $\checkmark$ & $\checkmark$ & $\checkmark$ & $\begin{array}{l}1 \\
0\end{array}$ & 72.72 \\
\hline Derse görsellik katar. & $\checkmark$ & $\checkmark$ & & $\checkmark$ & $\checkmark$ & & $\checkmark$ & $\checkmark$ & $\checkmark$ & & & $\begin{array}{l}1 \\
0\end{array}$ & 63.63 \\
\hline Zamandan tasarruf sağlar. & $\checkmark$ & $\checkmark$ & $\checkmark$ & & & $\checkmark$ & & $\checkmark$ & & $\checkmark$ & & $\begin{array}{l}1 \\
0\end{array}$ & 54.54 \\
\hline Öğretmenin işini kolaylaştırır. & $\checkmark$ & $\checkmark$ & $\checkmark$ & & & & $\checkmark$ & $\checkmark$ & & $\checkmark$ & & 6 & 54.54 \\
\hline Öğrencinin derse ilgisini çeker. & & & $\checkmark$ & $\checkmark$ & $\checkmark$ & $\checkmark$ & & & $\checkmark$ & $\checkmark$ & & 8 & 54.54 \\
\hline Dersin eğlenceli olmasını sağlar. & $\checkmark$ & & & $\checkmark$ & & $\checkmark$ & & & $\checkmark$ & & & 5 & 36.36 \\
\hline Kalıcı öğrenmeler sağlar. & $\checkmark$ & & & & $\checkmark$ & & $\checkmark$ & $\checkmark$ & & & & 5 & 36.36 \\
\hline
\end{tabular}

Öğretmen adayları ayrıca öğretimde BT kullanımının zamandan tasarruf sağlama (\%54.54), öğretmenin işini kolaylaştırma (54.54), öğrencinin derse ilgisini çekme (\%54.54), dersi eğlenceli kılma (\%36.36) ve kalıcı öğrenmeler sağlama (\%36.36) gibi yaralar sağlayacağı şeklinde görüş sunmuşlardır.

“..çünkü televizyon ya da bilgisayar çocukların dikkatini çekiyor kolayca” (Ö9k). "Öğretmenin dersi anlatmasını kolaylaştırıyor. Ders anlatımının daha görsel ve kalıcı olmasını sağlıyor” (Ö7k). “.. o konular öyle anlatılınca çocukların aklında daha çok kalır diye düşünüyorum” (Ö1k). 
Som, İ. (2017). The examination of the opinions of pre-service teachers on usage of the information technologies for educational purposes. International Journal of Social Sciences and Education Research, 3(3), 882898.

Tablo 4 incelendiğinde, öğretmen adaylarının görüşlerinin daha çok BT'nin ders anlatım sürecinde sağlayacağ 1 yararlarda yoğunlaştığı söylenebilir.

\section{4. Öğretmen adaylarının ögretimde BT kullanımının olumsuz taraflarına yönelik görüşleri}

Öğretmen adaylarına, öğretimde BT kullanımının olumsuz taraflarının neler olduğu sorulmuştur. Öğretmen adaylarının bu soruya ilişkin görüşleri Tablo 5 'te sunulmaktadır. Tablo 5 incelendiğinde öğretmen adaylarının çoğunluğu (\%63.63) öğretmenlerin BT kullanımındaki bilgi eksikliği ve öğrenci dikkatinin dağılmasının, öğretimde BT kaynaklı olumsuzluklara yol açabileceği şeklinde görüş bildirmişlerdir. Bununla ilgili öğretmen adayı görüşleri aşağıda verilmektedir:

“Ben şunu da düşünüyorum, öğretmenlerin çoğu bunu bilmiyor. Pek bir bilgi sahibi değiller bilişim teknolojileri ve nasıl entegre edebilecekleri konusunda. Genelde ögrretmenler eğitimin bir parçası olarak değil de, daha çok araç olarak... öğrencinin hiç kullanmadı̆̆ şekilde oluyor” (Ö11e). “... ya da herhangi bir bilgisi yoksa açtı̆̆ında ne yapacağım ben şimdi diyebilir. Öğretmenin önceden bir bilgisi olmall, eğitim almalı" (Ö7k).

Tablo 5. Öğretmen adaylarının öğretimde BT kullanımın olumsuz taraflarına yönelik görüşleri

\begin{tabular}{|c|c|c|c|c|c|c|c|c|c|c|c|c|c|}
\hline $\begin{array}{l}\text { Görüşler } \\
\text { (kodlar) }\end{array}$ & 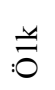 & $\frac{\breve{d}}{0}$ & $\frac{\ddot{m}}{0}$ & $\stackrel{0}{0}$ & $\stackrel{0}{0}$ & : & $\stackrel{4}{S}$ & $\frac{\ddot{\alpha}}{0}$ & $\stackrel{\ddot{\alpha}}{\circ}$ & $\frac{y}{0}$ & $\stackrel{0}{=}$ & $\mathrm{f}$ & $\%$ \\
\hline $\begin{array}{l}\text { Öğretmenlerin BT kullanımında bilgi } \\
\text { eksikliği }\end{array}$ & $\checkmark$ & $\checkmark$ & & & $\checkmark$ & $\checkmark$ & $\checkmark$ & & $\checkmark$ & & $\checkmark$ & $\begin{array}{l}1 \\
0\end{array}$ & 63.63 \\
\hline Öğrencilerin dikkatinin dağılması & $\checkmark$ & $\checkmark$ & $\checkmark$ & $\checkmark$ & & & & $\checkmark$ & $\checkmark$ & $\checkmark$ & & 7 & 63.63 \\
\hline $\begin{array}{l}\text { Sinıf yönetiminin olumsuz } \\
\text { etkilenmesi }\end{array}$ & $\checkmark$ & & & & $\checkmark$ & $\checkmark$ & & & & & & 4 & 27.27 \\
\hline $\begin{array}{l}\text { Farklı zeka alanına (sözel vb.) sahip } \\
\text { öğrencilere hitap etmemesi }\end{array}$ & & & & $\checkmark$ & & & $\checkmark$ & $\checkmark$ & & & & 3 & 27.27 \\
\hline $\begin{array}{l}\text { Teknik sorunların zaman kaybına } \\
\text { neden olması }\end{array}$ & $\checkmark$ & & & & & & & & & & & 1 & 9.09 \\
\hline
\end{tabular}

Öğrencilerin BT kullanımından kaynaklı dikkatinin dağılmasıyla ilgili olarak bir katılımcı şunu ifade etmiştir:

"Çocuklar slaytlara bakmaktan çok fazla uyarıcı olduğu için seni, önünde somut örnekleri çok fazla dinleyemezler. Ben şu an staja gittiğimde de, çocuklar belli bir yerden sonra orada bir şey oynuyorsa kesinlikle öğretmeni dinlemiyorlar. Dikkatleri dağllabiliyor"'(Ö3k).

Ayrıca katılımcılar; sınıf yönetiminin olumsuz etkilenmesi(\%27.27), farklı zeka alanına sahip öğrencilere hitap etmemesi (\%27.27) ve teknik sorunların zaman kaybına neden olmasını (\%9.09) öğretimde BT kullanımından doğabilecek olumsuzluklar olarak değerlendirmişlerdir.

\section{5. Öğretmen adaylarının ögretimde BT kullanım yeterliliklerine yönelik görüsşleri}

Öğretmen adaylarının BT kullanım yeterliliklerine ilişkin görüşleri sorulmuş ve görüşleri iki kategori altında Tablo 6'da sunulmaktadır. Tablo 6 incelendiğinde; yeterlilik durumu kategorisi altında öğretmen adaylarının tümü (\%100) öğretimde BT kullanımı hakkında kendilerini yeterli görmediklerini ifade etmiştir. Bu konuya ilişkin katılımcı görüşleri şu şekildedir: 
Som, İ. (2017). Öğretmen adaylarının öğretim amaçlı bilişim teknolojileri kullanımına ilişkin görüşlerinin incelenmesi. International Journal of Social Sciences and Education Research, 3(3), 882-898.

"Hayır, yeterli görmüyorum kesinlikle..."(Ö1k). "Bir dersimiz vardı seçmeli, ismini tam net olarak hatırlamıyorum. Orada gördüğ̈̈müz şeylerde sadece bir dönem boyunca görüyorsun hiçbir şekilde şu an kullanmaya çalışsam kullanamam bunu da biliyorum. $O$ programlarl, isimlerini net olarak bile hatırlamiyorum o yüzden o programlart kullanamam" (Ö2k). "Ben yeterli değilim şu an için çünkü I. hocanın gösterdiği birkaç şey aklımda kaldı" (Ö4e).

Tablo 6. Öğretmen adaylarının öğretimde BT kullanım yeterlilikleri hakkında görüşleri

\begin{tabular}{|c|c|c|c|c|c|c|c|c|c|c|c|c|c|}
\hline $\begin{array}{l}\text { Görüşler } \\
\text { (kategoriler) }\end{array}$ & $\stackrel{\ddot{Z}}{\overline{0}}$ & $\frac{\pi}{1}$ & $\frac{\ddot{m}}{0}$ & $\stackrel{\mathscr{0}}{0}$ & $\because$ & $\stackrel{\check{0}}{0}$ & $\stackrel{\frac{y}{S}}{0}$ & $\frac{y}{\infty}$ & $: \ddot{\circ}$ & $\frac{y}{0}$ & $\stackrel{0}{=0}$ & $\mathrm{f}$ & $\%$ \\
\hline \multicolumn{14}{|l|}{ Yeterlilik Durumu } \\
\hline Yeterli görmüyor & $\checkmark$ & $\checkmark$ & $\checkmark$ & $\checkmark$ & $\checkmark$ & $\checkmark$ & $\checkmark$ & $\checkmark$ & $\checkmark$ & $\checkmark$ & $\checkmark$ & $\begin{array}{l}1 \\
1 \\
\end{array}$ & 100 \\
\hline Yeterli görüyor & & & & & & & & & & & & 0 & 0 \\
\hline \multicolumn{14}{|l|}{ Kişisel Eğitim İhtiyact } \\
\hline $\begin{array}{l}\text { Yazılım (kodlama, } 3 \text { boyutlu } \\
\text { animasyon, çizim programları, } \\
\text { robot geliştirme, Office) }\end{array}$ & & & $\checkmark$ & & & $\checkmark$ & $\checkmark$ & & $\checkmark$ & & $\checkmark$ & 6 & 45.45 \\
\hline $\begin{array}{l}\text { BT kursuna (Halk eğitim, vb.) } \\
\text { katılım }\end{array}$ & $\checkmark$ & $\checkmark$ & $\checkmark$ & & & $\checkmark$ & & & $\checkmark$ & & & 6 & 45.45 \\
\hline $\begin{array}{l}\text { Web'in eğitsel kullanımı (web } \\
\text { 2.0, EBA) }\end{array}$ & & & & & & $\checkmark$ & $\checkmark$ & $\checkmark$ & & $\checkmark$ & & 4 & 36.36 \\
\hline Akıllı tahta kullanımı & $\checkmark$ & & & & $\checkmark$ & & $\checkmark$ & & & & & 3 & 27.27 \\
\hline
\end{tabular}

Diğer bir kategori olan kişisel eğitim ihtiyacı başlığı altında öğretmen adaylarına geliştirmek istedikleri beceriler sorulmuştur. Beş öğretmen adayı (\%45.45) programlama, 3 boyutlu animasyon ve çizim programlarını kullanma, robot geliştirme ve office yazılımları hakkında kendini geliştirmek istediğini belirtmiştir. Ayrıca beş öğretmen adayı (\%45.45) BT üzerine bir kursa katılma ihtiyacı duyduğunu ifade etmiştir. Dört öğretmen adayı (\%36.36) EBA kullanımı ve Web 2.0 uygulamalarını öğrenmek isterken, üç öğretmen adayı (\%27.27) akıllı tahta kullanımı hakkında eğitim almak istediğini söylemiştir.

"Ben böyle şeyleri kullanmay isterim ama fazla bir bilgim yok. Bunun için belki halk eğitimde bir kurs açılırsa gitmeyi de düşünüyorum” (Ö1k). "Web 2.0 diye bir şey var onu ögrenmek isterdim” (Ö6k). "Internette hangi sitenin güvenilir olduğu, hangisine güvenmemiz gerektiğiniz ögretmeleri lazım. EBA olsun daha bir sürü farkl fen siteleri var" (Ö7k).

Öğretmen adayları, eğitsel yazılım, mobil uygulamalar, EBA ve akıllı tahta kullanımına hakim olmadıkları ve bu konularda kendilerini geliştirmeye açık olduklarını vurgulamışlardır.

\section{6. Öğretmen adaylarının lisans eğitim sürecine yönelik önerileri}

Öğretmen adaylarına lisans eğitim sürecinin geliştirilmesine yönelik önerileri sorulmuştur. Görüşlerinden elde edilen veri ve bulgular Tablo 7'de özetlenmiştir. 
Som, İ. (2017). The examination of the opinions of pre-service teachers on usage of the information technologies for educational purposes. International Journal of Social Sciences and Education Research, 3(3), 882898.

Tablo 7'de görüldüğü üzere; beş öğretmen adayı (\%54.54) öğretmen yetiştirme lisans programlarında yer alan bilgisayar 1 ve 2 derslerinin branşa özgü düzenlenmesini önermişlerdir. Bu konuda öğretmen adaylarının önerileri şu şekildedir

"Belki bu alanda bilişim teknolojileriyle ilgili ders verilirken bölümlerde, bölümler baz alınarak verilirse... Bizim fakültemizde de genel bir eğitim veriliyor. Biz bilgisayar 2 dersini aldığımızda genel bir ders aldık. Bölümümüze özel bir uygulama yoktu. Bölümlere özel uygulama yapılması... Böyle bir derse ihtiyaç var. Şu şekilde olabilir. Okul öncesinde bilişim teknolojileri üzerine. Bilgisayar ögrretimi tamam, okul öncesi dönemde bilgisayarın kullanım amaçlarına yönelik olabilir. Programlar okul öncesine uygun olabilir" (Ö11e). "Lisans eğitiminde teknoloji dersleri biraz yetersiz. Hatırlyorum bilgisayar 1 sinavını, excelde fonksiyon sordular yani çok alakası bir şey. Ben fonksiyon niye kullanayım derste..." (Ö5e). "Mesela biz bilgisayar dersleri kapsamında sadece Office ögrrendik. Zaten onlar herkesin bildiği şeyler... Mesela EBA'ya girişi hiç ögrenmedik. Nasıl gireceğiz, öğrencilere nasıl bir şey să̆layabiliriz. Her ikisi de olmalı ama ögretmen olacaksak asıl kendi alanımızı bilmemiz gerekir" (Ö7k).

Tablo 7. Öğretmen adaylarının lisans eğitim sürecine yönelik önerileri

\begin{tabular}{|c|c|c|c|c|c|c|c|c|c|c|c|c|c|}
\hline $\begin{array}{l}\text { Görüşler } \\
\text { (kodlar) }\end{array}$ & $\stackrel{\ddot{Z}}{0}$ & $\frac{\breve{\pi}}{0}$ & $\frac{y}{m}$ & $\stackrel{0}{0}$ & $\stackrel{\mathscr{0}}{0}$ & : & $\stackrel{\ddot{N}}{0}$ & $\frac{y}{\infty}$ & $\frac{\pi}{\partial}$ & $\frac{\ddot{y}}{0}$ & $\stackrel{0}{=}$ & $\mathrm{f}$ & $\%$ \\
\hline $\begin{array}{l}\text { Lisans programlarındaki Bilgisayar } 1 \\
\text { ve } 2 \text { dersleri branşlara özgü } \\
\text { düzenlenmeli }\end{array}$ & & & $\checkmark$ & & $\checkmark$ & & $\checkmark$ & & & $\checkmark$ & $\checkmark$ & 5 & 54.54 \\
\hline $\begin{array}{l}\text { Fakülte tarafından öğretimde BT } \\
\text { kullanımına yönelik sertifika } \\
\text { eğitimleri düzenlenmesi }\end{array}$ & $\checkmark$ & $\checkmark$ & & $\checkmark$ & $\checkmark$ & $\checkmark$ & & & & & & 5 & 54.54 \\
\hline $\begin{array}{l}\text { Lisans programlarına öğretimde BT } \\
\text { kullanımıla ilgili dersler eklenmeli }\end{array}$ & & $\checkmark$ & & & & & $\checkmark$ & $\checkmark$ & & & & 6 & 27.27 \\
\hline $\begin{array}{l}\text { Lisans derslerine daha fazla BT } \\
\text { entegre edilmeli }\end{array}$ & & $\checkmark$ & & & & & $\checkmark$ & & & & & 2 & 18.18 \\
\hline
\end{tabular}

Ayrıca fakülte tarafından öğretimde BT kullanımına yönelik sertifika eğitimleri düzenlenmesine de $(\% 54.54)$ vurgu yapmışlardır. Bununla ilgili olarak bir katılımcı şu şekilde görüş belirtmektedir:

"Bilgisayar destekli ögretim diye bir sertifika almışlardı geçen sene arkadaşlarım, BÖTE düzenlemisti. Çok yararlı olduğunu söylüyorlar... Onun mesela tekrar yapılmasını çok isterdim”(Ö1k).

Üç öğretmen adayı (\%27.27) öğretmen yetiştirme lisans programlarına BT kullanımıyla ilgili derslerin eklenmesi ve 2 ögretmen adayı ise (\%18.18) lisans derslerine daha fazla BT entegre edilmesi yönünde önerilerde bulunmuştur.

\section{Sonuç, tartışma ve öneriler}

Araştırma sonuçları temel alındığında; bu araştırmaya katılan öğretmen adaylarının öğretimin BT ile bütünleştirilmesine ait tanımlamaları, Fatih projesi ve akıllı tahta ifadeleri ile sınırlı kalmıştır. Ayrıca tanımlar görüşme sırasında yöneltilen soru ifadesine benzerlik göstererek detaylandırılmamıştır. Öğretimde kullanılabilir BT araçları bilgisine ilişkin olarak 
Som, İ. (2017). Öğretmen adaylarının öğretim amaçlı bilişim teknolojileri kullanımına ilişkin görüşlerinin incelenmesi. International Journal of Social Sciences and Education Research, 3(3), 882-898.

öğretmen adaylarının çoğunluğu projeksiyon cihazı ve bilgisayarı örnek olarak vermiştir. Bunun sebebi olarak; orta öğretim ve yükseköğretim sırasında bu araçlarla sıkça karşılaşmış olmaları gösterilebilir. Bunların dışında kendi branşlarının öğretiminde faydalanabilecekleri hazır içerik, dinamik yazılımlar, eğitim sitelerine de örnekler sunmuşlardır. Öğretmen adaylarının öğretimde BT kullanımına yönelik olumlu görüşleri; öğretim süreçlerine yoğunlaşmıştır. Dersi görsellerle zenginleştirmesi, öğrenilenleri somutlaştırması, zamandan tasarruf sağlaması ve öğretmenin işini kolaylaştırmasını BT kullanımının olumlu yönleri olarak değerlendirilmiştir. Benzer çalışmalarda da; BT kullanımının faydalarıyla ilgili öğretmen adaylarının görüşleri görselliği arttırma ve öğretimi somutlaştırmaya yaradığ1 yönündedir (Akpınar, 2005; Baydaş \& Göktaş, 2916; Öçal \& Şimşek, 2017). Öğrenciler boyutunda ele alındığında; öğrencilerin ilgisini çekmesi ve dersi eğlenceli kılması da (Önal \& Çakır, 2016) olumlu olarak belirtilmiştir. Öğretmen adaylarının gelecekteki derslerinde BT kullanımına olumlu baktıkları sonucu çıkarılabilir (Baydaş \& Göktaş, 2016). Diğer taraftan, katılımcılar öğretmenlerin BT kullanımı konusunda bilgi eksikliğine dikkat çekerek, bunun öğretimde sorunlara yol açabileceğine vurgu yapmışlardır. Belirtilen diğer olumsuz taraflar; öğrenci dikkatinin dağılması, her öğrenciye hitap etmemesi ve teknik sorunların zaman kaybına yol açması şeklindedir. Ayrıca var olan araştırma sonuçlarıyla örtüşen bir sonuç olarak, öğretmen adayları öğretimde BT kullanımının sınıf yönetimini olumsuz etkilediği görüşünü savunmaktadır (Cüre \& Özdener, 2008; Demir \& Bozkurt, 2011).

Tüm öğretmen adayları kendilerini gelecek öğretimlerinde BT kullanımı konusunda yeterli görmediklerini belirtmiştir. BT kullanımı konusunda kendilerini geliştirmek için lisans eğitimi dışında halk eğitimi vb. gibi kurslara katılabileceklerini ifade etmişlerdir. Öğretmen adaylarının kendilerini geliştirmek için istekli oldukları görülmektedir. Office programı ve akıllı tahta kullanımının yanı sıra Web 2.0, robot geliştirme, kodlama, animasyon programları gibi daha yenilikçi uygulamaları öğrenmeye açık oldukları da ifade edilmiştir. Öğretmen adayları; öğretmen yetiştirme lisans programlarındaki Bilgisayar 1 ve 2 derslerinin branşlara özgü düzenlenmesini, fakülte tarafından öğretimde BT kullanımına yönelik sertifika eğitimleri düzenlenmesini ve BT kullanımına yönelik yeni dersler geliştirilmesini önermişlerdir. Ayrıca eğitim fakültesi öğretim üyeleri tarafından lisans derslerine daha fazla BT entegre edilmesi gerekliliğine de dikkat çekilmiştir. Bu bağlamda; öğretmenlere teknoloji kullanımını öğretmeyi hedefleyen hizmet içi eğitimlerin yetersiz olmasına bağlı olarak (Erduran \& Tartaroğlu, 2009) bu eğitimlerin lisans döneminde verilmesi gerekliliği ortaya çıkmaktadır (Yıldız, Sarıtepeci \& Seferoğlu, 2013; Banoğlu, Madenoğlu \& Dede, 2014). Nitekim alan yazın da; öğretmenlerin öğretimde teknolojiyi etkili olarak kullanamamalarının en büyük nedeni olarak hizmet öncesi dönemde konu ile ilgili sınırlı bilgi ve deneyim edinmeleri olduğu belirtilmektedir (Yıldırım, 2007; Kengwee Onchwari ve Wachira, 2008; Chai, Koh \& Tsai, 2010). Benzer olarak Keleş ve Turan (2015) çalışmasında; Fatih projesine yönelik olarak okullarda var olan teknolojiyi etkin kullanma becerisinin öğretmen adaylarına hizmet öncesi dönemde kazandırılmasının önemine vurgu yapmıştır. $\mathrm{Bu}$ araştırma sonuçlarıyla paralel olarak; teknolojik uygulama, yazılım vb. branşlara yönelik çeşitlilik göstermesinden dolayı hizmet öncesi dönemde verilecek bu eğitimlerin branşlara özgü düzenlenmesi ve uygulamalı olarak verilmesi önerilmektedir (Önal \& Çakır, 2016; Öçal \& Şimşek, 2017).

$\mathrm{Bu}$ araştırmanın sonuçları, öğretmen yetiştirme programlarında yer alan bilgisayar 1- 2 derslerinin, akıllı tahta, tablet vb. gibi araçların kullanımı, Web 2.0 teknolojilerinin eğitsel kullanımı, güncel yazılımların kullanımı, EBA eğitim portalına erişim ve kullanımını içerek şekilde gün- 
Som, İ. (2017). The examination of the opinions of pre-service teachers on usage of the information technologies for educational purposes. International Journal of Social Sciences and Education Research, 3(3), 882898.

cellenmesinin, öğretmen adaylarının başarılı bir BT entegrasyonu gerçekleştirmeleri için gereken nitelikleri edinmesi açısından faydalı olacağını göstermektedir. Ayrıca sınıf yönetimi dersinin kapsamı, teknolojinin sınıf ortamında doğuracağı sorunlar ve çözüm önerilerini içerecek şekilde genişletilebilir. Öğretmen adaylarının BT araçları ve uygulamalarına ilişkin farkındalıklarını arttırmaya yönelik lisans programı harici sertifika eğitimlerinin düzenlenmesi fakülteler tarafından desteklenebilir. Önemli bir nokta olarak bu ders ve eğitimlerin branşlara özgü yazılımlar, elektronik materyaller ve uygulamaları içerecek şekilde hazırlanması gerekmektedir. Bununla birlikte, eğitim fakültesi öğretim üyelerinin lisans derslerine daha fazla BT dahil etmeleri de önemli görülmektedir. Saygıner (2016), Çelik ve Karamustafaoğlu (2016); öğretmen adaylarının teknolojiden daha fazla faydalanan öğretmenler olarak yetiştirilmesinin, hizmet öncesi dönemde derslerin teknoloji ile bütünleşik bir biçimde planlanması ve kaynakların sunulması ile mümkün olduğunu belirtmektedir.

\section{Kaynakça}

Akkaya, R. (2016). Research on the development of middle school mathematics pre-service teachers' perceptions regarding the use of technology in teaching mathematics. Eurasia Journal of Mathematics, Science \& Technology Education, 12(4), 861-879.

Akpınar, Y. (2005). Bilgisayar destekli eğitimde uygulamalar. Ankara: Anı Yayınc1lık

Albirini, A. (2006). Teachers' attitudes toward information and communication technologies: The case of Syrian EFL teachers. Computers \& education, 47(4), 373-398.

Aslan, A., \& Chang, Z. H. U. (2015). Pre-service teachers' perceptions of ICT integration in teacher education in Turkey. TOJET: The Turkish Online Journal of Educational Technology, 14(3), 97-110.

Babbie, E. (2010). The practice of social research. (11. Ed.). USA: Wadsworth.

Banoglu, K., Madenoglu, C., Uysal, S. \& Dede, A. (2014). An Investigation of teachers' perceptions of the implementation of the FATIH Project (Eskisehir Province Case), Journal of Educational Sciences Research, 4(1), 39-58.

Baydaş, Ö., \& Göktaş, Y. (2016). Öğretmenlerin ve öğretmen adaylarının BT kullanma niyetleri: BT'yi okullarla bütünleştirmede anahtar faktörler. Mersin Üniversitesi Eğitim Fakültesi Dergisi, 12(1), 145162.

Bhasin, B. (2012). Integration of information communication technologies in enhancing teaching and learning. Contemporary educational technology, 3(2), 130-140.

Chai, C. S., Koh, J. H. L., \& Tsai, C. C. (2010). Facilitating preservice teachers' development of technological, pedagogical, and content knowledge (TPACK). Journal of Educational Technology \& Society, 13(4), 63-73

Creswell, J. W. (2007). Qualitative inquiry and research design: Choosing among five approaches. (2. Ed.) USA: Sage publications.

Cuban, L., Kirkpatrick, H., \& Peck, C. (2001). High access and low use of technologies in high school classrooms: Explaining an apparent paradox. American educational research journal, 38(4), 813-834.

Cüre, F., \& Özdener, N. (2008). Öğretmenlerin bilgi ve iletişim teknolojileri (BİT) uygulama başarıları ve BİT'e yönelik tutumları. Hacettepe Üniversitesi eğitim fakültesi dergisi, 34(34).

Celik, H. C., \& Kahyaoğlu, M. (2007). İlköğretim öğretmen adaylarının teknolojiye yönelik tutumlarının kümeleme analizi, Türk Eğitim Bilimleri Dergisi, 4(5), 571-586.

Çelik, H., \& Karamustafaoğlu, O. (2016). Science prospective teachers' self-efficacy and views on the use of information technologies in the teaching of physics concepts. Necatibey Eğitim Fakültesi Elektronik Fen ve Matematik Ĕ̈itimi Dergisi, 10(1), 182-208. 
Som, İ. (2017). Öğretmen adaylarının öğretim amaçlı bilişim teknolojileri kullanımına ilişkin görüşlerinin incelenmesi. International Journal of Social Sciences and Education Research, 3(3), 882-898.

Çetin, O., Önal, N., Gündüz, A. Y. (2015). Öğretmen adaylarının temel bilgi teknolojilerine yönelik görüşlerinin incelenmesi. Abant İzzet Baysal Üniversitesi Ĕgitim Fakültesi Dergisi, 15 (2), $59-83$.

Demir, S., \& Bozkurt, A. (2011). Primary mathematics teachers' views about their competencies concerning the integration of technology. Elementary Education Online, 10 (3), 850-860.

Earle, S., R. (2002). The Integration of instructional technology into public education: Promises and challenges. ET Magazine, 42(1), 5-13.

Erduran, A., \& Tataroğlu, B. (2009). Eğitimde akıllı tahta kullanımına iliş̧kin fen ve matematik öğretmen görüşlerinin karşılaştırılması. 9 th International Educational Technology Conference. Ankara.

Ertmer, P. A. (2005). Teacher pedagogical beliefs: The final frontier in our quest for technology integration?. Educational technology research and development, 53(4), 25-39.

Gibbone, A., Rukavina, P., \& Silverman, S. (2010). Technology integration in secondary physical education: Teachers' attitudes and practice. Journal of educational technology development and exchange, 3(1), 27-42.

Goktas, Y., Yildirim, S., \& Yildirim, Z. (2009). Main barriers and possible enablers of ICTs integration into pre-service teacher education programs. Educational technology \& society, 12(1), 193-204.

Hue, L. T., \& Ab Jalil, H. (2013). Attitudes towards ICT integration into curriculum and usage among university lecturers in Vietnam. Online submission, 6(2), 53-66.

Işıkoğlu, N. (2002). Integration of computer technoloy into early childhood curriculum. Phd Dissertation. The Pennsylvania State University, PA, USA.

Kayaduman, H., Sırakaya, M., \& Seferoğlu, S. S. (2011). Eğitimde FATïH projesinin öğretmenlerin yeterlik durumları açısından incelenmesi. Akademik bilişim, 11, 123-129.

Keengwe, J., Onchwari, G., \& Wachira, P. (2008). Computer technology integration and student learning: barriers and promise. Journal of Science of Education Technology, 17, 560-565.

Keleş, E., \& Turan, E. (2015). Öğretmenlerin firsatları arttırma ve teknolojiyi iyileştirme hareketi (FATIH) hakkındaki görüşleri. Turkish Journal of Education, 4(2),17-28.

Koksal, M. S., Yaman, S., \& Saka, Y. (2016). Analysis of Turkish prospective science Teachers' perceptions on technology in education. Australian Journal of Teacher Education, 41(1), 21-41.

Kubiatko, M., Usak, M., Yilmaz, K., \& Tasar, M. F. (2010). A cross-national study of czech and turkish university students attitudes towards ICT used in science subjects. Journal of Baltic science education, 9(2), 119-134.

Kurt, S. (2014). Creating technology-enriched classrooms: implementational challenges in Turkish education, Learning, Media and Technology, 39 (1), 90-106.

Lim, C. P., \& Khine, M. S. (2006). Managing teachers' barriers to ICT integration in Singapore schools. Journal of technology and Teacher Education, 14(1), 97-125.

Mandell, S., Sorge, H. D. \& Russell, D., J. (2002). TIPs for technology integration. TechTrednds, 46 (5).

MEB (2017). Fatih Projesi. http://fatihprojesi.meb.gov.tr// adresinden 20.02.2017 tarihinde alınmıştır.

Miles, M. B., Huberman, A. M. (1984). Qualitative data analysis: A source book of new methods. Bervely Hills, C. A.: Sage.

Mueller, J., Wood, E., Willoughby, T., Ross, C., \& Specht, J. (2008). Identifying discriminating variables between teachers who fully integrate computers and teachers with limited integration. Computers \& education, 51(4), 1523-1537.

Mwalongo, A. (2011). Teachers' perceptions about ICT for teaching, professional development, administration and personal use. International Journal of Education and development using information and communication Technology, 7(3), 36-49.

Öçal, M. F. \& Şimşek, M. (2017). Matematik öğretmen adaylarının FATiH projesi ve matematik eğitiminde teknoloji kullanımına yönelik görüşleri. Turkish Online Journal of Qualitative Inquiry, $8(1), 91-121$. 
Som, İ. (2017). The examination of the opinions of pre-service teachers on usage of the information technologies for educational purposes. International Journal of Social Sciences and Education Research, 3(3), 882898.

Önal, N. \& Çakır, H. (2016). Ortaokul matematik öğretmenlerinin matematik öğretiminde bilişim teknolojileri kullanımına ilişkin görüşleri. Mersin Üniversitesi Eğitim Fakültesi Dergisi, 12(1), $76-94$.

Özen, R. (2013). Öğretmen adaylarının eğitimi ve teknoloji kullanımı: Bir durum çalışması. International Journal of Human Sciences, 10(2), 147-162.

Patton, M. Q. (2014). Nitel araştırma ve değerlendirme yöntemleri. (M. Bütün \& S. B. Demir, Çev.). Ankara: A Pegem Akademi.

Saban, A. (2007). Okul teknolojisi, planlaması ve koordinasyon (1.bask1). Ankara: Pegem A Yayıncılık.

Saygıner, Ş. (2016). Öğretmen adaylarının bilgisayar yeterlilik düzeyleri ile teknolojiye yönelik algıları arasındaki ilişkinin çeşitli değişkenler açısından incelenmesi. Mustafa Kemal Üniversitesi Sosyal Bilimler Enstitüsü Dergisi, 13(34), 298-312.

Shoepp, K. (2005). Barriers to Technology Integration in a Technology-Rich Environment. Learning and Teaching in Higher Education: Gulf Perspectives, Vol. 2(1), 1-24.

Tezci, E. (2009). Teachers' effect on ICT use in education: The Turkey sample. Procedia-social and behavioral sciences, 1(1), 1285-1294.

Türnüklü, A. (2000). Eğitimbilim araştırmalarında etkin olarak kullanılabilecek nitel bir araştırma tekniği: Görüşme. Kuram ve Uygulamada Eğitim Yönetimi Dergisi, 6(4), 543-559.

Uşun, S. (2003). Undergraduate students' attitudes towards educational uses of Internet. Interactive Educationa Multimedia, 7, 46-62.

Ward, L., Parr, M., J. (2010). Revisiting and reframing use: Implications for the Integration of ICT. Computers and Education, 54, 113-122.

Yıldırım, S. (2007). Current utilization of ICT in Turkish basic education schools: A review of teacher's ICT use and barriers to integration. International journal of instructional media, 34(2), 171.

Yıldırım, A. \& Şimşek, H. (2013). Sosyal bilimlerde nitel araştırma yöntemleri. (9. baskı). Ankara: Seçkin Yayıncılık.

Yıldız, H., Sarıtepeci, M., \& Seferoğlu, S. S. (2013). FATİH projesi kapsamında düzenlenen hizmet-içi eğitim etkinliklerinin öğretmenlerin mesleki gelişimine katkılarının ISTE öğretmen standartları açısından incelenmesi. Hacettepe Üniversitesi Ĕ̆itim Fakültesi Dergisi, Özel sayı, 1, 375-392. 
Som, İ. (2017). Öğretmen adaylarının öğretim amaçlı bilişim teknolojileri kullanımına ilişkin görüşlerinin incelenmesi. International Journal of Social Sciences and Education Research, 3(3), 882-898.

\section{Extended Abstract in English}

\section{Introduction}

Information technologies (IT) find more space in learning environments each day as the most up-to-date visual and audiovisual tools for increasing the quality of teaching, achieving learning objectives, preparing individuals for real life and providing effective learning. Despite the national initiatives aimed at improving the use of technology in instruction, the integration of IT in learning environments has not been achieved at the desired level (Mwalongo, 2011). As a reason for that Kurt (2014) remarks; although there are appropriate technological tools in school, teachers can be unsuccessful in their educational use. As it is seen; the inclusion of IT into teaching is directly or indirectly affected by many dynamic variables like teachers, students, administrators etc. except for the availability of hardware and software tools (Cuban, Kirkpatrick \& Peck, 2001; Ertmer, 2005; Yıldırım, 2007). It is stated that teachers have a key role in the effective use of IT for educational purposes. The rapid change of technology, especially FATIH Project which improves the technological conditions in the schools in Turkey and increases the usage of these technologies in teaching, makes it important to take into account the opinions and willingness of prospective teachers to use educational technology as future practitioners (Kayaduman, Sırakaya, Seferoğlu, 2011; Banoglu, Madenoglu, Uysal \& Dede, 2014).

In this research, it is aimed to reveal the opinions of the pre-service teachers on the use of IT in teaching for predicting their use in their future instruction. The views of pre-service teachers play an important role in using the technologies for instruction and integration IT into their practices (Çelik \& Kahyaoğlu, 2007). The results of this research may contribute to the development of undergraduate programs in order to provide the necessary qualifications for preservice teachers within this scope.

\section{Method}

This research has a phenemological design. The study group consists of a total of 11 preservice teachers attending the last class at an education faculty in Istanbul in the 2016-2017 academic year. The research data were collected through a semi-structured interview form consisting of 11 open ended questions developed by the researcher. Interviews were conducted face to face based on the principle of voluntary participation. In the analysis of the data obtained from the interviews the content analysis technique is used which provides access to the concepts and correlations that can explain the collected data (Yıldırım \& Şimşek, 2013). Two specialists have been provided to code a randomly selected data set. Correspondence percentage was found .77 which indicates reliability in content analysis. In order to increase the validity of the study, interview transcripts were sent to participants by e-mail to review their responses and confirm their correctness. Participants were quoted directly to some of the statements they said during the interview.

\section{Findings}

\subsection{Definitions of pre-service teachers relating to integration of IT into teaching}

Six of the participants $(54.54 \%)$ define the integration of IT into teaching as presentation of teaching and technology together. Two of the participants responded with a single statement as FATIH Project(18.18\%) and using smart board (18.18\%). One participant (\%9.09) defines as 
Som, İ. (2017). The examination of the opinions of pre-service teachers on usage of the information technologies for educational purposes. International Journal of Social Sciences and Education Research, 3(3), 882898.

the presence of technology serving the objectives. within the scope of the course Another participant (\%9.09) explains the integration of technology into teaching as STEM applications.

\subsection{Pre-service teachers' knowledge of utilizable IT}

The majority of participants stated projection (63.63\%) and computers $(54.54 \%)$ as available technology. Five participants out of eleven (\%45.45) stated Educational Information Network (EBA) and three of them stated Smart Boards as utilizable. Besides this they gave a limited number of examples of educational portals, mobile applications and various educational web sites.

\subsection{Pre-service teachers' views on the contributions of using IT in teaching}

The vast majority of the participants $(72.72 \%)$ indicated that the use of IT would make the learning more concrete. In addition, seven participants (63.63\%) stated that the use of IT was beneficial in terms of visualization. Participants also pointed out that integrating IT provides benefits such as saving time (\%54.54), attracting interest of students during the lesson (\%54.54), making learning more entertaining and permanent (\%36.36).

\subsection{Pre-service teachers' views on the downsides of using IT in teaching}

The majority of participants (63.63\%) reported that teachers' lack of knowledge and student distraction may lead to IT-related disadvantages in teaching. In addition, the participants also stated disruption of classroom management (\%27.27), not to suit for students with different intelligence areas (\%27.27) and loss of time due to technical problems (\%9.09) as negations that could arise from the use of IT in teaching.

\subsection{Pre-service teachers' views on their proficiency in IT use in teaching}

All of the participants $(100 \%)$ stated that they lack adequate about using IT in teaching. Five participants out of eleven (45.45\%) stated that they want to improve themselves about programming, using 3D animation and drawing programs, robot development and office software. In addition, five participants $(45.45 \%)$ indicated that they needed to participate in a course on IT. Three participants $(36.36 \%)$ said they want to get training about the use of EBA (educational information network) and Web 2.0 applications, while another three participants $(27.27 \%)$ need a training about smart board use.

\subsection{Pre-service teachers' suggestions for undergraduate teacher education}

Five participants out of eleven (\%54.54) suggested that Computer 1 and Computer 2 courses in undergraduate teacher education programs should be organized specific to subject area. They (54.54\%) also emphasized that faculties should organize certificate trainings for IT use in teaching. Three participants $(\% 27.27)$ proposed the inclusion of courses related to IT use in teacher education undergraduate programs and two participants suggested that faculty members should integrate more IT into undergraduate courses.

\section{Conclusion, discussion and implication}

Based on the results of this research; it is concluded that pre-service teachers participated in this research have positive views about contributions of educational technology (Baydaş \& Göktaş, 2016). Another result of this research is that pre-service teachers need to get a training in the usage of smart boards, web 2.0 technologies, contemporary softwares and EBA education 
Som, İ. (2017). Öğretmen adaylarının öğretim amaçlı bilişim teknolojileri kullanımına ilişkin görüşlerinin incelenmesi. International Journal of Social Sciences and Education Research, 3(3), 882-898.

portal. Updating of the Computer $1 \& 2$ courses in the undergraduate programs including above mentioned needs by participants will be useful for pre-service teachers to acquire the qualifications needed for successful IT integration. It can be also suggested based on the results that the scope of the classroom management course should be expanded to include the problems can arise by technology use in the classroom environment and solutions to them.

Additionally, this study illustrated that certificate trainings for pre-service teachers should be organized by faculties, which increase their awareness of IT tools and applications. As an important point, these courses and trainings need to be specific to the subject area (Önal \& Çakır, 2016; Öçal \& Şimşek, 2017). It is also important that faculty members include more IT in their undergraduate courses. 